\title{
Evaluation of Health-Related Quality of Life in Lung Cancer Patients in Greece and Associations with Demographic and Medical Characteristics
}

\author{
Constantinos Togas, George Alexias, Fotios Anagnostopoulos \\ Department of Psychology, Panteion University of Social and Political Sciences, Athens, Greece \\ Email: togascostas@yahoo.gr
}

How to cite this paper: Togas, C., Alexias, G. and Anagnostopoulos, F. (2019) Evaluation of Health-Related Quality of Life in Lung Cancer Patients in Greece and Associations with Demographic and Medical Characteristics. Journal of Biosciences and Medicines, 7, 17-31.

https://doi.org/10.4236/jbm.2019.710002

Received: September 2, 2019

Accepted: October 6, 2019

Published: October 9, 2019

Copyright $\odot 2019$ by author(s) and Scientific Research Publishing Inc. This work is licensed under the Creative Commons Attribution International License (CC BY 4.0).

http://creativecommons.org/licenses/by/4.0/

\begin{abstract}
Lung cancer is a common type of cancer. The aim of this study was to examine Health-Related Quality of Life (HRQOL) in lung cancer patients and the demographic/medical characteristics that are related to it. A crosssectional study was conducted in "Sotiria" Chest Diseases Hospital, Greece, with a sample of 200 lung cancer patients. Patients completed a composite questionnaire including demographic/medical information, EORTC-QLQ-C30 and EORTC-QLQ-LC13. The duration of the study was 17 months (April 2014 to August 2015). SPSS v.25 was used for the analysis of data. Mean age was 68.5 years, $70.5 \%$ were men, $81 \%$ were married, $84 \%$ had Non-Small Cell Lung Cancer (NSCLC) and 16\% had Small Cell Lung Cancer (SCLC). Patients evaluated their HRQOL as moderate $(M=51.71)$. The predominant symptoms were fatigue, pain, dyspnoea, insomnia, and appetite loss. Most of the symptoms were negatively correlated with the functional scales of EORTCQLQ-C30. Better perceived health and HRQOL were related to the absence of recurrence and higher educational level. All functional scales were significantly affected by recurrence. Gender, income status, metastases, information about the diagnosis and months elapsed since diagnosis significantly affected only some functional scales. These results can be used to identify patients at high risk for having poor HRQOL and to improve their therapy plan. Future research is suggested, in order to further investigate and clarify the study's results.
\end{abstract}

\section{Keywords}

Lung Cancer, HRQOL, Demographic Characteristics, Medical Characteristics, EORTC-QLQ-C30 


\section{Introduction}

Lung cancer is the most common type of cancer worldwide (about $12.3 \%$ of all new cases-the same percentage as breast cancer) and the leading cause of cancer mortality in both sexes [1].

There are two main histological types of lung cancer, non-small cell lung cancer (NSCLC; approximately $85 \%$ - 90\% of lung cancers) and small cell lung cancer (SCLC; about $10 \%-15 \%$ of lung cancers), with the latter having worse prognosis and quality of life. Moreover, lungs are a common site for metastases from other organs (e.g. breast, colon, etc.). Approximately two of three patients diagnosed with lung cancer are over 65 years old and the average age at the time of diagnosis is about 70 years [2]. Lung cancer has one of the poorest prognoses of all human malignancies and its five-year survival rate is very low (18\% in USA and $12.6 \%$ in Europe) [3]. This fact can influence patients' responses to the diagnosis, with a decline in Health-Related Quality of Life (HRQOL) [4].

HRQOL is a multidimensional concept reflecting the persons' physical health, psychological state, level of independence, social relationships, personal beliefs and their relationship to salient features of their environment [5]. HRQOL in patients with neoplastic/malignant disease is correlated with the clinical outcome and survival [6] [7] and depends on the type of cancer, tumor localization and stage, comorbidities, type of treatment, prognosis and survival [8]. In addition, it is of great importance in advanced-terminal cancer patients, as therapy is palliative for them [9].

Lung cancer patients experience a significant burden due to comorbidities and symptoms and have decreased quality of life [10] [11] compared with the general population or with survivors of other cancer types [12]. The main symptoms that adversely affect HRQOL are dyspnoea (related to cancer), persistent cough, the shortness of breath, fatigue, chest pain, diarrhea, sleep disturbance, and appetite loss [11] [13].

In Lemonnier's et al. study (with a sample of NSCLC patients) the lowest score was observed in diarrhea scale and the highest score in fatigue scale. Concerning the functioning dimensions, the highest score was observed in cognitive functioning and the lowest in role functioning [7]. Larsson et al. examined patients with advanced NSCLC and found that global health status and physical, role, and emotional functioning were markedly deteriorated. Moreover, the most prominent symptoms were dyspnoea, fatigue, coughing, insomnia, appetite loss, and pain [14].

Several demographic and clinical characteristics of lung cancer patients that influence HRQOL have been investigated, but the results are inconclusive [4]. Women seem to have poorer HRQOL [14] and higher rates of depression prior to treatment than men [15]. Marital status seems not to affect HRQOL [16]. Older age predicts poorer HRQOL [17] but in other studies, poorer HRQOL has been positively correlated with younger age [14]. Higher education has been associated with better HRQOL in several studies [18] [19]. The advanced stages of the disease are related to a decline in HRQOL, due to multiple symptoms [14]. 
The role of metastases is also important. The patients with metastases experience impaired quality of life [20]. Concerning smoking, Brown Johnson et al. [4] argue that it does not affect HRQOL significantly, but Pierzynski et al. [19] have found that former/current smokers report worse HRQOL than never smokers.

Chest surgery is a main component of treatment [8] and chronic pain is the most common complication [21]. HRQOL is still significantly impaired at $6-12$ months after surgery [22]. In particular, its physical domains deteriorate early after surgery but improve to baseline by 6 months after surgery [21] [22]. Extensive surgery is related to deterioration in the quality of life [22] [23] and to significant decline in physical, social and role functionality [24].

Chemotherapy is accepted as a standard of care for advanced NSCLC and seems to have a positive impact on HRQOL [25]. Palliative chemotherapy is also beneficial to the HRQOL in the advanced stages of the disease [11].

High-dose radiotherapy or concurrent chemo-radiation seems to be a welltolerated treatment option with preservation of HRQOL [26]. Langendijk et al. [27] examined NSCLC patients receiving radical radiotherapy and found that the HRQOL response rates were excellent for haemoptysis, good for chest pain, arm/shoulder pain and appetite loss, and poor for dyspnoea, cough, and fatigue. Scores varied from $35 \%$ for physical and role functioning to $55 \%$ for social and cognitive functioning, while the score for global QOL was 36\%.

The aim of this study was to examine HRQOL in lung cancer patients and the demographic and medical characteristics that are related to it. The recognition of these factors will help health professionals to provide better care to these patients.

Based on the findings of the literature presented above, it was hypothesized that: 1) lung cancer patients would have poor quality of life (Hypothesis 1);2) there are differences in quality of life according to the patients' demographic characteristics (e.g. gender, marital status, level of education) (Hypothesis 2); 3) there are differences in quality of life according to the patients' medical characteristics (e.g. histological type, therapy etc.) (Hypothesis 3); 4) several symptoms (such as dyspnoea and coughing) have more negative impact on functionality and quality of life than other symptoms (like soremouth and dysphagia) (Hypothesis 4).

\section{Methods}

\subsection{Procedure}

A cross-sectional study was conducted with a convenience sample of 200 lung cancer patients admitted to the Oncology Unit and the outpatient clinic of the 3rd Department of Athens University School of Medicine (which specializes in cancer treatment) in "Sotiria" Chest Diseases Hospital, Athens, Greece. "Sotiria" is one of the largest specialized hospitals in Greece and patients from all over the country are being treated in it. The research was conducted in this hospital in order to achieve a representative database. The duration of the study was 17 months (April 2014 to August 2015). The sample consisted of patients who came 
in the oncology unit and in the outpatient clinic, based on the daily program. Patients were coming to the day clinic to receive chemotherapy, to be prescribed medications, and to be further examined. These patients completed the questionnaires before starting their daily therapy. Patients who had finished their treatment visited the outpatient clinic for follow-up and completed the questionnaires after their examination.

The sample consisted of diagnosed lung cancer patients, regardless of histological type and stage. Patients with secondary lung cancer, serious psychiatric symptoms, and those who could not participate due to their impaired health status (as it was ascertained by the doctors or the medical records) were excluded.

A composite questionnaire was used, which included sociodemographic data, information about the medical history, as well as EORTC QLQ-C30 and EORTC QLQ-LC13. The sociodemographic data were completed during the interview and the information about the medical history were obtained later from the individuals' medical records and from the hospital's files. Patients were informed in detail about the purpose of the study, were given an information sheet, signed the consent form and were included in the study.

\subsection{Measures}

EORTC QLQ-C30: It consists of 30 items divided into functional scales (physical, role, emotional, cognitive, social functioning) and symptom scales (fatigue, nausea/vomiting, pain, dyspnoea, insomnia, appetite loss, constipation, diarrhoea, financial difficulties). Moreover, there is a global health status/HRQOL scale. Total score ranges from 0 to 100. A high score in functional scales and in the global health status/HRQOL scale represents a high/healthy level of functioning and a high HRQOL. In the contrary, a high score in a symptom scale/item represents a high level of symptomatology [28]. The questionnaire has been used in a wide range of cancer studies. Its Greek version presents good validity and reliability (especially for the functional scales) [29].

EORTC QLQ-LC13: The lung cancer module consists of 13 questions assessing lung cancer-associated symptoms (cough, haemoptysis, dyspnoea, site specific pain), treatment-related side effects (sore mouth, dysphagia, peripheral neuropathy, alopecia) and pain medication. Its scoring is identical to that for the symptom scales of the EORTC QLQ-C30.

EORTC QLQ-C30 in combination with the EORTC QLQ-LC13 is the most frequently used tool for assessing HRQOL in lung cancer patients [30]. These tools have sensitivity to the imaging of changes in symptoms during treatment [28] and have presented satisfactory reliability and validity [31].

In this study, EORTC QLQ-C30 and EORTC QLQ-LC13 were used after obtaining a permission from the European Organisation for Research and Treatment of Cancer.

\subsection{Data Analysis}

Data analysis was performed using SPSS v.25.0. Kolmogorov-Smirnov test was 
used to examine the normality of continuous variables. The analysis included descriptive statistics and Spearman's correlation coefficients for the examination of linear correlations among quantitative variables. Mann-Whitney and KruskalWallis tests were used to check statistically significant differences between two or more than two groups, respectively. Non-parametric tests were used because of the non-normal distribution of the data. Moreover, multiple linear regressions with the Global health status/HRQOL (QL) scale and the functional scales of EORTC-QLQ-C30 as the dependent variables were performed. Statistical significance level (p-value) was set to $5 \%$.

\subsection{Ethics}

The hospital's Research and Ethics Committee gave approval for the study and a signed informed consent was obtained from all participants. All patients took part on a voluntary basis and were not remunerated for their participation. They were informed that they could stop completing the questionnaire at any time they wished. They were also assured that the collected data would be used only for the purpose of the study, and that their decision to withdraw would not compromise the standards of the care provided.

\section{Results}

According to the eligibility criteria, 222 patients were selected to participate in the study and 200 of them accepted (response rate: 91\%). Non-participation was mainly due to time constraints.

Participant's mean age was 68.5 years (Min: 48, Max: 91, Range: 43). The mean time since diagnosis was 13.5 months (Min: 1, Max: 60, Range: 59 ). 28\% of the patients had no other diseases, $25 \%$ suffered from another disease (e.g., coronary heart disease, diabetes mellitus) and $26.5 \%$ from two other diseases. The rest demographic and medical characteristics of the sample are presented in Table 1 . The majority of the patients were men (70.5\%), 65 - 74 years old (43.5\%), married (81\%), illiterate or primary school graduates and had adequate income status. Concerning their medical characteristics, the vast majority of them suffered from NSCLC (84\%) and were smokers (86.9\%), informed about their diagnosis $(95 \%)$ and had no metastases $(75.5 \%)$ or recurrence $(90 \%)$. In addition, most of them were subjected to therapy in Day clinic (84.5\%) and the most common type of therapy was chemotherapy, as monotherapy (52.5\%).

Descriptive statistics and mean differences between patients with SCLC and NSCLC in the questionnaires' score are presented in Table 2. Scores in all functional scales of EORTC-QLQ C30 were > 48. Low scores were observed in RF, $\mathrm{SF}$, and PF scales and high score in $\mathrm{CF}$ and EF scales. There were no significant differences between NSCLC and SCLC patients. The symptoms that mainly affected patients were fatigue, pain, dyspnoea, insomnia, and appetite loss. In addition, financial difficulties greatly affected patients. Patients evaluated their quality of life as moderate during last week $(M=51.71)$. Patients with SCLC had 
significantly higher scores in the "Coughing" subscale than patients with N-SCLC, and patients with N-SCLC had higher scores in the "Peripheral neuropathy" subscale than patients with SCLC.

Age and months elapsed since diagnosis was not significantly correlated with functional and symptom scales of EORTC QLQ-C30. The majority of the symptoms were negatively correlated with the functional scales (Table 3). The strongest

Table 1. Demographic and medical characteristics of the sample $(\mathrm{N}=200)$.

\begin{tabular}{|c|c|c|}
\hline & $\mathbf{N}$ & Percentage (\%) \\
\hline \multicolumn{3}{|l|}{ Gender } \\
\hline Men & 141 & $70.5 \%$ \\
\hline Women & 59 & $29.5 \%$ \\
\hline \multicolumn{3}{|l|}{ Age group } \\
\hline$<65$ years & 63 & $31.5 \%$ \\
\hline $65-74$ years & 87 & $43.5 \%$ \\
\hline$\geq 75$ years & 50 & $25 \%$ \\
\hline \multicolumn{3}{|l|}{ Marital status } \\
\hline Single & 10 & $5 \%$ \\
\hline Married & 162 & $81 \%$ \\
\hline Divorced & 13 & $6.5 \%$ \\
\hline Widow/widower & 15 & $7.5 \%$ \\
\hline \multicolumn{3}{|l|}{ Educational level } \\
\hline Illiterate-Primary school & 108 & $54 \%$ \\
\hline Secondary school & 44 & $22 \%$ \\
\hline Lyceum & 34 & $17 \%$ \\
\hline Higher education & 9 & $4.5 \%$ \\
\hline \multicolumn{3}{|l|}{ Income status } \\
\hline Good & 16 & $8 \%$ \\
\hline Adequate & 135 & $67.5 \%$ \\
\hline Bad/poor & 49 & $24.5 \%$ \\
\hline \multicolumn{3}{|l|}{ Setting of service provision } \\
\hline Day clinic & 169 & $84.5 \%$ \\
\hline Outpatient clinic & 31 & $15.5 \%$ \\
\hline \multicolumn{3}{|l|}{ Histological type } \\
\hline NSCLC & 168 & $84 \%$ \\
\hline SCLC & 32 & $16 \%$ \\
\hline \multicolumn{3}{|l|}{ Knowledge about diagnosis } \\
\hline Yes & 190 & $95 \%$ \\
\hline No & 10 & $5 \%$ \\
\hline
\end{tabular}




\section{Continued}

\begin{tabular}{ccc}
\hline $\begin{array}{c}\text { Smoking } \\
\text { Yes }\end{array}$ No & 173 & $86.9 \%$ \\
Therapy (during the study or earlier) & 26 & $13.1 \%$ \\
Radiotherapy (as monotherapy) & & \\
Chemotherapy (as monotherapy) & 1 & $0.5 \%$ \\
$\begin{array}{c}\text { Combination of radiotherapy-chemotherapy } \\
\text { Combination of chemotherapy-surgical resection }\end{array}$ & 105 & $52.5 \%$ \\
Combination of radiotherapy-chemotherapy- \\
surgical resection & 40 & $20 \%$ \\
Metastases (in brain, bones, liver, etc). & 13 & $20.5 \%$ \\
Yes & & $6.5 \%$ \\
No & 49 & $24.5 \%$ \\
Yes & 151 & $75.5 \%$ \\
No & & $10 \%$ \\
\hline
\end{tabular}

Table 2. Descriptive statistics for EORTC QLQ-C30 and EORTC QLQ-LC 13 and differences between patients with NSCLC and SCLC.

\begin{tabular}{|c|c|c|c|c|}
\hline & $\begin{array}{c}\text { All } \\
\text { patients }\end{array}$ & $\begin{array}{l}\text { NSCLC } \\
\text { patients }\end{array}$ & $\begin{array}{c}\text { SCLC } \\
\text { patients }\end{array}$ & $\begin{array}{c}p \\
\text { (NSCLC vs. } \\
\text { SCLC } \\
\text { patients) }\end{array}$ \\
\hline & $\begin{array}{c}\text { Mean (SD) } \\
\text { Range } 0-100\end{array}$ & $\begin{array}{c}\text { Mean (SD) } \\
\text { Range } 0-100\end{array}$ & $\begin{array}{c}\text { Mean (SD) } \\
\text { Range } 0-100\end{array}$ & \\
\hline \multicolumn{5}{|l|}{$\begin{array}{l}\text { EORTC QLQ-C30 } \\
\text { Functional scales }\end{array}$} \\
\hline Physical functioning (PF) & $56.83(1.73)$ & $57.22(24.95)$ & $54.79(21.67)$ & NS \\
\hline Role functioning (RF) & $48.92(1.97)$ & $49.21(28.30)$ & $47.40(25.44)$ & NS \\
\hline Emotional functioning (EF) & $68.25(1.60)$ & $68.65(23.29)$ & $66.15(19.28)$ & NS \\
\hline Cognitive functioning (CF) & $62.00(1.86)$ & $61.81(26.64)$ & $63.02(24.95)$ & NS \\
\hline Social functioning (SF) & $50.50(1.95)$ & $49.90(28.52)$ & $53.65(22.29)$ & NS \\
\hline \multicolumn{5}{|l|}{$\begin{array}{c}\text { EORTC QLQ-C30 } \\
\text { Symptom scales }\end{array}$} \\
\hline Fatigue (FA) & $46.89(26.54)$ & $46.37(26.79)$ & $49.65(25.42)$ & NS \\
\hline Nausea and vomiting (NV) & $21.08(23.66)$ & $21.63(24.37)$ & $18.23(19.57)$ & NS \\
\hline Pain (PA) & $35.08(23.48)$ & $35.52(23.82)$ & $32.81(21.79)$ & NS \\
\hline Dyspnoea (DY) & $34.17(22.28)$ & $34.33(22.32)$ & $33.33(22.40)$ & NS \\
\hline Insomnia (SL) & $32,50(31.25)$ & $31.75(31.97)$ & $36.46(27.25)$ & NS \\
\hline Appetite loss (AP) & $28.33(33.71)$ & $26.59(32.74)$ & $37.50(37.63)$ & NS \\
\hline Constipation (CO) & $25.00(33.21)$ & $24.21(33.57)$ & $29.17(31.40)$ & NS \\
\hline Diarrhoea (DI) & $6.50(18.21)$ & $6.55(18.69)$ & $6.25(15.70)$ & NS \\
\hline Financial difficulties (FI) & $57.00(29.44)$ & $56.55(30.03)$ & $59.37(26.42)$ & NS \\
\hline
\end{tabular}




\section{Continued}

\begin{tabular}{ccccc}
\hline $\begin{array}{c}\text { EORTC QLQ-C30 } \\
\text { Global health status/HRQOL } \\
\text { (QL) }\end{array}$ & $51.71(1.36)$ & $51.79(19.88)$ & $51.30(16.00)$ & NS \\
$\begin{array}{c}\text { EORTC QLQ-LC 13 } \\
\text { Dyspnoea (LCDY) }\end{array}$ & $39.56(1.68)$ & $39.15(24.35)$ & $41.67(20.35)$ & NS \\
Coughing (LCCO) & $22.33(1.83)$ & $20.83(25.97)$ & $30.21(24.48)$ & 0.025 \\
Haemoptysis (LCHA) & $4.00(1.02)$ & $3.37(12.96)$ & $7.29(20.28)$ & NS \\
Soremouth (LCSM) & $15.83(1.61)$ & $16.47(23.36)$ & $12.50(20.30)$ & NS \\
$\begin{array}{c}\text { Dysphagia (LCDS) } \\
\text { Peripheral neuropathy } \\
\text { (LCPN) }\end{array}$ & $18.00(1.75)$ & $18.65(24.93)$ & $14.58(23.85)$ & NS \\
Alopecia (LCHR) & $18.50(2.06)$ & $20.44(30.06)$ & $8,33(20.74)$ & 0.039 \\
Pain in chest (LCPC) & $25.00(2.54)$ & $23.61(34.67)$ & $32.29(42.00)$ & NS \\
Pain in arm or shoulder & $29.33(1.56)$ & $30.16(22.56)$ & $25.00(18.93)$ & NS \\
$\quad$ (LCPA) & $25.17(1.99)$ & $26.59(28.62)$ & $17.71(25.38)$ & NS \\
Pain in other parts (LCPO) & $19.33(1.95)$ & $18.25(26.76)$ & $25.00(31.68)$ & NS \\
\hline
\end{tabular}

Note: NS = Non-significant.

negative correlations were recorded between Fatigue (FA) and Physical functioning (PF) $(-0.717, \mathrm{p}<0.01)$, (Role functioning (RF) $(-0.676, \mathrm{p}<0.01)$ and Social functioning $(\mathrm{SF})(-0.644, \mathrm{p}<0.01)$. These results indicate that fatigue is a predominant symptom with significantly negative impact on HRQOL.

Almost all symptoms evaluated by EORTC-QLQ-C30 and EORTC-QLQLC13 correlated negatively with perceived health/quality of life (Table 4). In EORTC QLQ-C30, the strongest negative correlation was recorded with fatigue (FA) $(-0.672, \mathrm{p}<0.01)$ and Dyspnoea (DY)) $(-0.478, \mathrm{p}<0.01)$, while in EORTC-QLQ-LC13 the strongest negative correlation was recorded with Dyspnoea (DY)) $(-0.570, \mathrm{p}<0.01)$, Pain in arm or shoulder (LCPA)) $(-0.382$, p < $0.01)$ and Coughing $(\mathrm{LCCO}))(-0.363, \mathrm{p}<0.01)$.

Most of the symptoms (evaluated with EORTC QLQ-LC13) were significantly correlated with dyspnoea and coughing. Symptoms that were negatively correlated with perceived health/quality of life were dyspnoea, fatigue, pain and nausea and vomiting (Table 5).

According to multiple regressions (Table 6), patients with higher education and those who had not a recurrence had better perceived health/ quality of life and physical functioning than patients with lower educational level and those who had recurrence. In addition, recurrence was significantly related to all functional scales of EORTC-QLQ-C30 in the same direction. Women presented better role functioning than men and patients with good income status had better cognitive and social functioning than patients with bad/adequate income status. Patients without metastases had better role, cognitive and social functioning than patients with metastases, and those who were not informed about their di- 
agnosis had better cognitive functioning than those who were informed. Months elapsed since diagnosis was positively associated with cognitive and social functioning.

\section{Discussion}

This study aimed to assess the HRQOL in a sample of lung cancer patients in

Table 3. Correlations between EORTC QLQ-C30 and EORTC-QLQ-LC13.

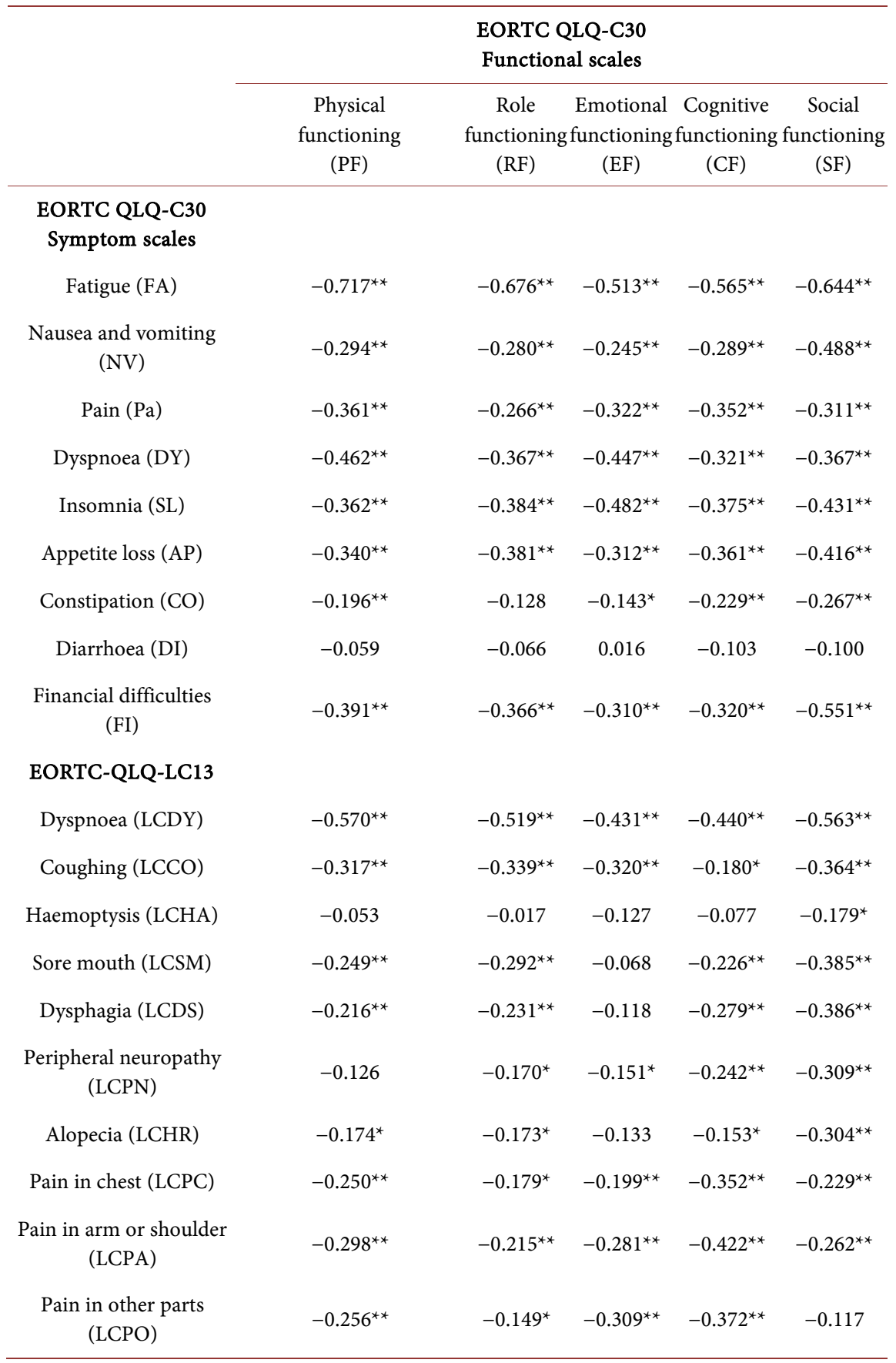

Note: ${ }^{* *}$ Correlation is significant at the 0.01 level (2-tailed). ${ }^{*}$ Correlation is significant at the 0.05 level (2-tailed). 
Table 4. Correlations of Global health status/HRQOL (QL) scale with symptom scales of EORTC QLQ-C30 and EORTC-QLQ-LC13.

\begin{tabular}{|c|c|}
\hline & $\begin{array}{c}\text { Global health status/HRQOL (QL) } \\
\text { scale of EORTC-QLQ C30 }\end{array}$ \\
\hline \multicolumn{2}{|l|}{$\begin{array}{l}\text { EORTC QLQ-C30 } \\
\text { Symptom scales }\end{array}$} \\
\hline Fatigue (FA) & $-0.672^{\star \star}$ \\
\hline Nausea and vomiting (NV) & $-0.400^{\star *}$ \\
\hline Pain (PA) & $-0.417^{\star \star}$ \\
\hline Dyspnoea (DY) & $-0.478^{\star *}$ \\
\hline Insomnia (SL) & $-0.427^{\star *}$ \\
\hline Appetite loss (AP) & $-0.406^{\star *}$ \\
\hline Constipation (CO) & $-0.247^{\star *}$ \\
\hline Diarrhoea (DI) & -0.123 \\
\hline Financial difficulties (FI) & $-0.392^{\star *}$ \\
\hline \multicolumn{2}{|l|}{ EORTC-QLQ-LC13 } \\
\hline Dyspnoea (LCDY) & $-0.570^{* *}$ \\
\hline Coughing (LCCO) & $-0.363^{* *}$ \\
\hline Haemoptysis (LCHA) & -0.136 \\
\hline Sore mouth (LCSM) & $-0.308^{\star *}$ \\
\hline Dysphagia (LCDS) & $-0.258^{* *}$ \\
\hline Peripheral neuropathy (LCPN) & $-0.329^{* *}$ \\
\hline Alopecia (LCHR) & $-0.234^{* *}$ \\
\hline Pain in chest (LCPC) & $-0.266^{* *}$ \\
\hline Pain in arm or shoulder (LCPA) & $-0.382^{\star *}$ \\
\hline Pain in other parts (LCPO) & $-0.270^{\star *}$ \\
\hline
\end{tabular}

Note: ${ }^{* *}$ Correlation is significant at the 0.01 level (2-tailed).

Table 5. Correlations of dyspnoea and cough with the other symptoms of EORTC-QLQLC13.

\begin{tabular}{ccc}
\hline & $\begin{array}{c}\text { EORTC-QLQ-LC13 } \\
\text { Dyspnoea (LCDY) }\end{array}$ & $\begin{array}{c}\text { EORTC-QLQ-LC13 } \\
\text { Coughing (LCCO) }\end{array}$ \\
\hline $\begin{array}{c}\text { EORTC-QLQ-LC13 } \\
\text { Other symptoms }\end{array}$ & $0.489^{* *}$ & \\
Coughing (LCCO) & $0.171^{*}$ & $0.238^{* *}$ \\
Haemoptysis (LCHA) & $0.286^{* *}$ & $0.254^{* *}$ \\
Sore mouth (LCSM) & $0.325^{* *}$ & $0.167^{*}$ \\
Dysphagia (LCDS) & 0.102 & 0.134 \\
Peripheral neuropathy (LCPN) & $0.214^{* *}$ & 0.098 \\
Alopecia (LCHR) & $0.351^{* *}$ & $0.160^{*}$ \\
Pain in chest (LCPC) & $0.241^{* *}$ & 0.087 \\
Pain in arm or shoulder (LCPA) & $0.224^{* *}$ & 0.109 \\
Pain in other parts (LCPO) & & \\
\hline
\end{tabular}

Note: ${ }^{*}$ Correlation is significant at the 0.01 level $\left(2\right.$-tailed). ${ }^{*}$ Correlation is significant at the 0.05 level (2-tailed). 
Table 6. Multiple regressions with the Global health status/HRQOL (QL) scale and the functional scales of EORTC-QLQ C30 as the dependent variables.

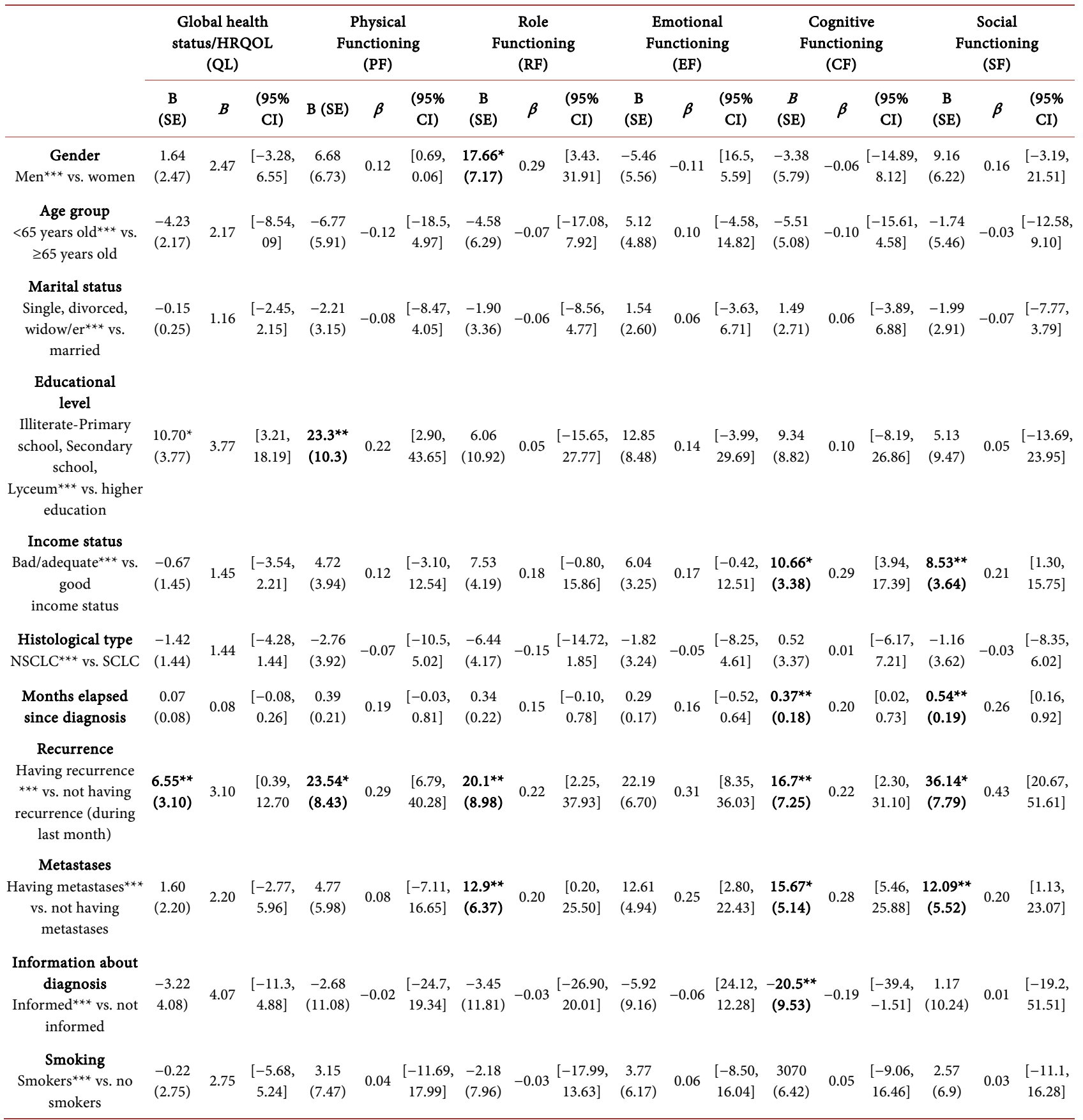

Note: ${ }^{*} \mathrm{p}<{ }^{\star} 0.01 ;{ }^{* *} \mathrm{p}<0.05 ;{ }^{* *}$ Reference category, Number of observation $=200$.

Greece and to explore its relationship with sociodemographic and medical va riables. The literature review suggested that very few studies have examined this relationship in lung cancer patients in Greece and this fact highlights the novelty of the study.

The main results of this research indicate that lung cancer patients report a moderate functionality and quality of life. Consequently, hypothesis 1 was par- 
tially confirmed. Low score was recorded in RF, SF, and PF scales and high in $\mathrm{CF}$ and EF scales. Similar results about CF and RF scales have been reported by Lemonnier et al. [7].

Hypotheses 2 and 3 were also partially confirmed, by inspection of the results. Contrary to other findings [2], no significant differences were found between SCLC and NSCLC patients.

Better perceived health and quality of life were related to the absence of recurrence and higher educational level. The findings of the educational level are similar to that found in other studies [14] [18] [19]. Patients who had not metastases had higher score in role, cognitive and social functioning than patients who had metastases. Similar results about impaired HRQOL of patients with metastases have been reported by Trippoli et al. [20].

Concerning gender, although other researchers have reported that women have poorer HRQOL than men [14] [15], in this study, women had a higher score than men only in role functioning and not in perceived health/quality of life.

In addition, marital status did not affect HRQOL, as found by Jatoi et al. [16]. Findings of other studies about the effect of age on HRQOL are contradictory [14] [17] and in the present study, age was not significantly related to HRQOL. Income status has not been examined as a determinant of HRQOL in other studies. This study indicated the crucial role of this variable in HRQOL outcomes (especially in cognitive and social functioning). As far as smoking is concerned, there are mixed results [4] [19] and in this study, no differences were found between smokers and no smokers in HRQOL.

The type of therapy was not significantly related to the perceived health/quality of life of the patients, although extensive surgery is related to greater deterioration in the quality of life [22] [23] [24]. This may be due to the fact that most patients were subjected to combined types of therapies and none was subjected to surgical resection as monotherapy. The stage of cancer was not recorded but months elapsed since diagnosis (as a related variable) was not significantly correlated with HRQOL. Other researchers have reported that the advanced stages of the disease are related to a decline in HRQOL, due to multiple symptoms [13].

The majority of the symptoms were negatively correlated with the functional scales and hypothesis 4 was confirmed. The main symptoms that adversely affected the quality of life were fatigue, pain, dyspnoea, coughing, insomnia, appetite loss, pain in chest etc. Similar results have been reported in other studies, too [7] [11] [12]. Coughing and dyspnoea adversely affected the quality of life, as it has been reported in other studies [11]. Diarrhea does not seem to greatly affect HRQOL and similar results have been reported by Lemonnier et al. [7].

The strengths of this study include the novelty of the topic examined for the Greek population with cancer, the ability to assess the relationship of various demographic/medical factors with HRQOL, and the use of standardized/reliable questionnaires. As for the research limitations, it must be highlighted that this is a cross-sectional study, in which it isn't possible to examine causal relations. 
Furthermore, the stage of the disease was not recorded for some patients (because there was a need for restaging the disease or this information didn't exist in the medical records).

In conclusion, this study identified the moderate level of HRQOL in lung cancer patients in Greece and the several demographic and medical factors that were significantly related to it. These results can be used to identify patients at high risk for having poor HRQOL.

In addition, the evaluation of the quality of life could improve the therapy plan and the referrals to psychologists and to other health professionals.

Future research is suggested, in order to further investigate and clarify the study's results. Similar research could be conducted with different research designs (e.g. prospective studies, case-control studies, etc.) and larger sample. Moreover, it would be helpful to compare lung cancer patients with patients having other sites of cancer. Surveys could also focus on patients with particular needs and characteristics, e.g. on patients with high comorbidity, who were never smokers etc.

\section{Conflicts of Interest}

The authors declare no conflicts of interest regarding the publication of this paper.

\section{References}

[1] World Cancer Research Fund (2018). https://www.wcrf.org/dietandcancer/cancer-trends/worldwide-cancer-data

[2] American Cancer Society (2018). http://www.cancer.org/cancer/lungcancer/index

[3] European Lung Foundation (2017). http://www.erswhitebook.org/chapters/lung-cancer

[4] Brown Johnson, C.G., Brodsky, J.L. and Cataldo, J.K. (2014) Lung Cancer Stigma, Anxiety, Depression, and Quality of Life. Journal of Psychosocial Oncology, 32, 59-73. https://doi.org/10.1080/07347332.2013.855963

[5] World Health Organisation (WHO) (2018). https://www.who.int/healthinfo/survey/whoqol-qualityoflife/en

[6] Montazeri, A., Milroy, R., Hole, D., McEwen, J. and Gillis, C.R. (2001) Quality of Life in Lung Cancer Patients: As an Important Prognostic Factor. Lung Cancer, 31, 233-240. https://doi.org/10.1016/S0169-5002(00)00179-3

[7] Lemonnier, I., Guillemin, F., Arveux, P., Clément-Duchêne, C., Velten, M., Woronoff-Lemsi, M.C., Baumann, C., et al. (2014) Quality of Life after the Initial Treatments of Non-Small Cell Lung Cancer: A Persistent Predictor for Patients' Survival. Health and Quality of Life Outcomes, 12, Article No. 73. https://doi.org/10.1186/1477-7525-12-73

[8] Postolache, P., Munteanu, A., Nemeş, R.M. and Cojocaru, D.C. (2014) Pulmonary Rehabilitation and Quality of Life in Lung Cancer Patients. Revista Medico-chirurgicală a Societații de Medici şi Naturalişti din Iaşi, 118, 293-300.

[9] Salvo, N., Hadi, S., Napolskikh, J., Goh, P., Sinclair, E. and Chow, E. (2009) Quality of Life Measurement in Cancer Patients Receiving Palliative Radiotherapy for 
Symptomatic Lung Cancer: A Literature Review. Current Oncology, 16, 16-28. https://doi.org/10.3747/co.v16i2.376

[10] Yorke, J., Brettle, A. and Molassiotis, A. (2012) Nonpharmacological Interventions for Managing Respiratory Symptoms in Lung Cancer. Chronic Respiratory Disease, 9, 117-129. https://doi.org/10.1177/1479972312441632

[11] Davis, M.P. (2012) The Emerging Role of Palliative Medicine in the Treatment of Lung Cancer Patients. Cleveland Clinic Journal of Medicine, 79, eS51-eS55. https://doi.org/10.3949/ccjm.79.s2.11

[12] Clauser, S.B., Arora, N.K., Bellizzi, K.M., Haffer, S.C., Topor, M. and Hays, R.D. (2008) Disparities in HRQOL of Cancer Survivors and Non-Cancer Managed Care Enrollees. Health Care Financing Review, 29, 23-40.

[13] Dean, G.E., Redeker, N.S., Wang, Y.J., Rogers, A.E., Dickerson, S.S., Steinbrenner, L.M. and Gooneratne, N.S. (2013) Sleep, Mood, and Quality of Life in Patients Receiving Treatment for Lung Cancer. Oncology Nursing Forum, 40, 441-451. https://doi.org/10.1188/13.ONF.441-451

[14] Larsson, M., Ljung, L. and Johansson, B.B. (2012) Health-Related Quality of Life in Advanced Non-Small Cell Lung Cancer: Correlates and Comparisons to Normative Data. European Journal of Cancer Care, 21, 642-649. https://doi.org/10.1111/j.1365-2354.2012.01346.x

[15] Hopwood, P. and Stephens, R.J. (2000) Depression in Patients with Lung Cancer: Prevalence and Risk Factors Derived from Quality-of-Life Data. Journal of Clinical Oncology, 18, 893-903. https://doi.org/10.1200/JCO.2000.18.4.893

[16] Jatoi, A., Novotny, P., Cassivi, S., Clark, M.M., Midthun, D., Patten, C.A., Yang, P., et al. (2007) Does Marital Status Impact Survival and Quality of Life in Patients with Non-Small Cell Lung Cancer? Observations from the Mayo Clinic Lung Cancer Cohort. Oncologist, 12, 1456-1463. https://doi.org/10.1634/theoncologist.12-12-1456

[17] Gridelli, C., Perrone, F., Nelli, F., Ramponi, S. and De Marinis, F. (2001) Quality of Life in Lung Cancer Patients. Annals of Oncology, 12, S21-S25. https://doi.org/10.1093/annonc/12.suppl_3.S21

[18] Lam, K., Chow, E., Zhang, L., Wong, E., Bedard, G., Fairchild, A., Bottomley, A., et al. (2013) Determinants of Quality of Life in Advanced Cancer Patients with Bone Metastases Undergoing Palliative Radiation Treatment. Support Care Cancer, 21, 3021-3030. https://doi.org/10.1007/s00520-013-1876-6

[19] Pierzynski, J.A., Ye, Y., Lippman, S.M., Rodriguez, M.A., Wu, X. and Hildebrandt, M.A.T. (2018) Socio-Demographic, Clinical, and Genetic Determinants of Quality of Life in Lung Cancer Patients. Scientific Reports, 8, Article No. 10640. https://doi.org/10.1038/s41598-018-25712-1

[20] Trippoli, S., Vaiani, M., Lucioni, C. and Messori, A. (2001) Quality of Life and Utility in Patients with Non-Small Cell Lung Cancer. Quality-of-Life Study Group of the Master 2 Project in Pharmacoeconomics. Pharmacoeconomics, 19, 855-863. https://doi.org/10.2165/00019053-200119080-00007

[21] Cannon, J., Win, T. and Ferguson, M. (2008) Long-Term Quality of Life after Lung Resection. Thoracic Surgery Clinics, 18, 81-91. https://doi.org/10.1080/07347332.2013.855963

[22] Balduyck, B., Hendriks, J., Sardari Nia, P., Lauwers, P. and Van Schil, P. (2009) Quality of Life after Lung Cancer Surgery: A Review. Minerva Chirurgica, 64, 655-663.

[23] Poghosyan, H., Sheldon, L.K., Leveille, S.G. and Cooley, M.E. (2013) Health-Related 
Quality of Life after Surgical Treatment in Patients with Non-Small Cell Lung Cancer: A Systematic Review. Lung Cancer, 81, 11-26. https://doi.org/10.1016/j.lungcan.2013.03.013

[24] Chambers, A., Routledge, T., Pilling, J. and Scarci, M. (2010) In Elderly Patients with Lung Cancer Is Resection Justified in Terms of Morbidity, Mortality and Residual Quality of Life? Interactive Cardio Vascular and Thoracic Surgery, 10, 1015-1021. https://doi.org/10.1510/icvts.2010.233189

[25] Mannion, E., Gilmartin, J.J., Donnellan, P., Keane, M. and Waldron, D. (2014) Effect of Chemotherapy on Quality of Life in Patients with Non-Small Cell Lung Cancer. Support Care Cancer, 22, 1417-1428. https://doi.org/10.1007/s00520-014-2148-9

[26] Pijls-Johannesma, M., Houben, R., Boersma, L., Grutters, J., Seghers, K., Lambin, P., De Ruysscher, D., et al. (2009) High-Dose Radiotherapy or Concurrent Chemo-Radiation in Lung Cancer Patients Only Induces a Temporary, Reversible Decline in QOL. Radiotherapy and Oncology, 91, 443-448. https://doi.org/10.1016/j.radonc.2009.02.010

[27] Langendijk, J.A., Aaronson, N.K., de Jong, J.M., ten Velde, G.P., Muller, M.J., Lamers, R.J., Wouters, E.F., et al. (2001) Prospective Study on Quality of Life before and after Radical Radiotherapy in Non-Small-Cell Lung Cancer. Journal of Clinical Oncology, 19, 2123-2133. https://doi.org/10.1200/JCO.2001.19.8.2123

[28] Aaronson, N.K., Ahmedzai, S., Bergman, B., Bullinger, M., Cull, A., Duez, N.J., et al. (1993) The European Organization for Research and Treatment of Cancer QLQ-C30: A Quality of Life Instrument for Use in International Clinical Trials in Oncology. Journal of the National Cancer Institute, 85, 365-375. https://doi.org/10.1093/jnci/85.5.365

[29] Mystakidou, K., Tsilika, E., Parpa, E., Kalaidopoulou, O., Smyrniotis, V. and Vlahos, L. (2001) The EORTC Core Quality of Life Questionnaire (QLQ-C30: Version 3.0) in Terminally Ill Cancer Patients under Palliative Care: Validity and Reliability in a Hellenic Sample. International Journal of Cancer, 94, 135-139.

https://doi.org/10.1002/ijc.1439

[30] Claassens, L., van Meerbeeck, J., Coens, C., Quinten, C., Ghislain, I., Sloan, E.K., Bottomley, A., et al. (2011) Health-Related Quality of Life in Non-Small-Cell Lung Cancer: An Update of a Systematic Review on Methodologic Issues in Randomized Controlled Trials. Journal of Clinical Oncology, 29, 2104-2120. https://doi.org/10.1200/JCO.2010.32.3683

[31] Nicklasson, M. and Bergman, B. (2007) Validity, Reliability and Clinical Relevance of EORTC QLQ-C30 and LC13 in Patients with Chest Malignancies in a Palliative Setting. Quality of Life Research, 16, 1019-1028. https://doi.org/10.1007/s11136-007-9210-8 